\title{
PERBEDAAN PERUBAHAN BERAT BADAN PADA BAYI UMUR 6 - 12 BULAN YANG DILAKUKAAN DAN TIDAK DILAKUKAN PIJAT BAYI
}

\author{
DAMARATI, SKM \\ Prodi D-III Kebidanan Universitas PGRI Adi Buana Surabaya
}

\begin{abstract}
ABSTRAK
Pertambahan berat badan bayi biasanya cepat pada usia antara 1-6 bulan. Namun memasuki 6 bulan keatas, biasanya menjadi lambat. Salah satu faktor penyebabnya adalah bayi sudah mulai banyak bergerak, seperti belajar berguling, merangkak dan kemudian berjalan. Tujuan penelitian mengetahui perbedaan perubahan berat badan pada bayi umur 612 bulan yang dilakukan dan tidak dilakukan pijat bayi di BPS Ny. Siti Maryam, Amd.Keb Surabaya.

Jenis penelitian yang digunakan adalah observasional bersifat analitik. Rancang bangun penelitian yang digunakan dalam penelitian ini adalah kohort. Penelitian dilakukan di BPS Ny Siti Mariam, Amd.Keb Surabaya, pada bulan juli s/d september 2011. Variabel independen adalah perilaku pijat bayi. Variabel dependen adalah berat badan bayi. Tehnik pengambilan sampel menggunakan tehnik simple random sampling. Subyek penelitian ini adalah 28 responden. Tehnik pengumpulan dan menggunakan lembar observasi, timbangan.

Berdasarkan hasil penelitian dari 28 responden yang dilakukan pijat 18 responden dengan prosentasenya $64,3 \%$ dan terdapat 19 responden dengan terjadi peningkatan berat badan dengan prosentasenya 67,9\%. Dari hasil pengujian tersebut diketahui hasil uji chi square adalah 0,035>0,05. Dari hasil penelitian ini dapat disimpulkan bahwa ada perbedaan perubahan berat badan pada bayi umur 6-12 bulan yang dilakukan dan tidak dilakukan pijat bayi
\end{abstract}

Kata Kunci : Bayi 6-12 bulan, pijat bayi, berat badan

\section{PENDAHULUAN}

Pertumbuhan adalah bertambahnya

ukuran dan jumlah sel serta jaringan intra seluler, yang berarti bertambahnya ukuran tubuh sebagian atau keseluruhan sehingga dapat diukur dengan satuan panjang dan 
berat (Depkes RI, 2010). Pertambahan berat badan bayi biasanya cepat pada usia antara 1-6 bulan. Namun memasuki 6 bulan keatas, biasanya menjadi lambat. Salah satu faktor penyebabnya adalah bayi sudah mulai banyak bergerak, seperti belajar berguling, merangkak dan kemudian berjalan. Salah satu cara yang dapat dilakukan oleh orang tua untuk mengoptimalkan pertumbuhan masa bayi adalah dengan melakukan stimulasi tumbuh kembang yang lebih awal pada bayi, salah satu contoh stimulasi adalah dengan melakukan pijat bayi, karena pijat bayi dapat merangsang peningkatan nafsu makan sehingga dapat meningkatkan berat badan bayi secara optimal.

Angka kematian bayi (AKB) merupakan indikator yang digunakan untuk menentukan derajat kesehatan masyarakat, baik pada tingkat provinsi maupun nasional (Depkes RI, 2010). Berdasarkan penelitian Lembaga Kesehatan Dunia “ World Health Organization" (WHO) memperkirakan di seluruh dunia terdapat kematian bayi pada khususnya neonatus sebesar 10 juta jiwa per tahun. Menurut data Survei Demokrafi Kesehatan Indonesia (SDKI, 2007) Angka Kematian Bayi (AKB) di Indonesia 34 per 1000 kelahiran hidup.

Angka Kematian Bayi di Jawa Timur Pada tahun 2011, di Surabaya Angka Kematian Bayi sebesar 20 per 1000 kelahiran hidup per tahun. Menurut Soetjiningsih kebutuhan dasar anak terbagi atas kebutuhan fisik-biomedis (asuh), kebutuhan emosi/kasih sayang (asih) dan kebutuhan akan stimulasi mental (asah), kebutuhan fisik meliputi: pangan atau gizi yang merupakan kebutuhan terpenting. Kebutuhan dasar anak kedua adalah kebutuhan emosi dan kasih sayang. Pada tahun-tahun pertama kehidupan hubungan yang erat, mesra dan selaras antara ibu dengan anak merupakan syarat mutlak untuk menjamin tumbuh kembang anak baik fisik, mental maupun psikososial (Soetjiningsih 2009). 


\section{METODE}

Penelitian ini adalah penelitian observasional analitik, dimana peneliti melakukan analisis dinamika korelasi antara fenomena atau antara faktor resiko dengan faktor efek. Rancang bangun yang digunakan adalah kohort. Penelitian ini dilakukan di BPS Ny. Siti Mariam, Amd. Keb jln Bratang Gede no 17 Surabaya pada bulan juli s/d september 2011. Populasi dalam penelitian ini adalah semua bayi yang berumur 6-12 bulan di BPS Ny. Siti Mariam, Amd. Keb sebanyak 30 bayi. Kemudian Memasukan data hasil tabulasi ke dalam tabel distribusi frekuensi sesuai dengan variabel tersebut. Kemudian memasukan dalam tabel silang dan tabel frekuensi. Selanjutnya membuat hipotesis nol dan variabel diuji menggunakan uji

Chi- Kuadrat $\left(x^{2}\right)$ dengan tingkat signifikansi atau tingkat kemaknaan ( $\alpha$ ) $=0,05$. Dimana pada variabel perbedaan perubahan berat badan diuji dengan uji Chi- Square dengan korelasi kontinyuitas dari yates, jika $x^{2}$ hitung $>x^{2}$ Maka H1

diterima yang berarti ada perbedaan perubahan berat badan pada bayi umur 612 bulan yang dilakukan dan tidak dilakukan pijat bayi.

\section{HASIL PENELITIAN}

Tabel Distribusi Responden berdasarkan Perlakuan Pijat di BPS Ny, Siti Mariam Amd. Keb. Surabaya, padabulan September tahun 2011.

\begin{tabular}{|l|l|c|}
\hline Perlakuan Pijat & Jumlah & $\%$ \\
\hline DilakukanPijat & 18 & 64.3 \\
\hline Tidak Dilakukan & 10 & 35.7 \\
\hline Total & & \\
\hline \multicolumn{2}{|l|}{ Sumber :Data Primer 2011 } \\
\hline
\end{tabular}

Hal ini sesuai dengan teori Pijat bayi akan menimbulkan bayi cepat lapar, sehingga bayi tersebut sering mengkonsumsi ASI. Makin banyak ASI yang dikeluarkan, maka produksi ASI semakin meningkat. Hal ini terjadi karena dalam memproduksi ASI berlaku hukum 
Supply Demand. Menurut Gichara (2006) nada dua aspek dalam tubuh bayi yang dipengaruhi ketika pemijatan Menanamkan kepercayaan berlangsung, yaitu aspek emosional dan fisik. 1. Aspek Emosional, aspek emosional tersebut meliputi : Menanamkan rasa percaya diri, bebas dan aman, dan seimbang antara orang tua dan anak, Menguatkan hubungan antara orang tua dan anak serta memberikan percaya diri dalam mengurus anak-anaknya, Mengurangi hormone kartisol (pemicu stress) dalam aliran darah atau menjaga kestabilannya selama pemijatan. 2 Aspek fisik, Aspek fisik meliputi : Melancarkan pencernaan dan pembuangan sehingga bayi terangsang untuk menyusui dengan baik, Menghindari sembelit, kolik dan diare, Meningkatkan pertumbuhan dan perkembangan bayi. Bayi dapat dipijat setelah bayi lahir. Semakin cepat bayi dipijat akan semakin besar menfaatnya terlebih bila dilakukan setiap hari sampai bayi berumur 6-7 bulan (Gichara, 2006). Sebaiknya pemijatan dilakukan pagi hari sebelum mandi, bisa juga malam hari yang cukup melelahkan. Tindakan pijat dikurangi seiring dengan bertambahnya usia bayi. Sejak usia enam bulan, pijat dua hari sekali sudah memadai (Prasetyono, 2009).

Tabel Distribusi Berat badan bayi yang dilakukan dengan tidak dilakukan pijat, di BPS Ny, Siti Mariam Amd. Keb. Surabaya, pada bulan September tahun 2011.

\begin{tabular}{|c|c|c|}
\hline Keberhasilan & Jumlah & $\%$ \\
\hline Naik & 19 & $67.9 \%$ \\
\hline Turun & 9 & $32.1 \%$ \\
\hline Total & 28 & $100 \%$ \\
\hline
\end{tabular}

Sumber :Data Primer 2011

Hal ini sesuai dengan teori

Pertumbuhan adalah bertambahnya ukuran fisik dan struktur tubuh dalam arti sebagian atau seluruhnya karena adanya multiplikasi bertambahnya banyak sel - sel tubuh dan juga karena bertmbah besarnya sel. Jadi, pertumbuhan lebih ditekankan pada pertambahan ukuran fisik seseorang, yaitu 
menjadi lebih besar atau lebih matang

bentuknya, seperti pertambahan ukuran

berat badan, tinggi badan, dan lingkar

kepala ( IDAI, 2007 ).

Tabel Tabulasi Silang Perbedaan perubahan berat badan pada bayi umur 6 - 12 bulan yang dilakukan dan tidak dilakukan piijat bayi di BPS Ny, Siti Mariam Amd. Keb. Surabaya, pada bulan September tahun 2011.

\begin{tabular}{|c|c|c|c|c|c|}
\hline \multirow{2}{*}{ Pijat } & \multicolumn{2}{|c|}{ Naik } & Turun & \multicolumn{2}{|c|}{ Total } \\
\hline & & & & & $\%$ \\
\hline $\begin{array}{l}\text { Dilakukan } \\
\text { Pijat }\end{array}$ & 5 & $\begin{array}{l}3.3 \\
\%\end{array}$ & $\begin{array}{l}6.7 \\
\%\end{array}$ & 8 & $100 . \%$ \\
\hline $\begin{array}{l}\text { Tidak } \\
\text { Dilakukan } \\
\text { pijat }\end{array}$ & & $0 \%$ & $0 \%$ & 0 & $100 \%$ \\
\hline Total & 9 & $\begin{array}{l}7.9 \\
\%\end{array}$ & $\begin{array}{l}2.1 \\
\%\end{array}$ & 8 & $100 \%$ \\
\hline
\end{tabular}

$\mathrm{p}=0.035>\alpha=0.05$

Sumber :Data Primer 2011

Hal ini sesuai dengan teori Pijat bayi

adalah terapi sentuhan tertua yang di kenal manusia dan yang paling populer. Pijat adalah seni perawatan kesehatan dan pengobatan yang dipraktekan sejak berabadabad silam lamanya. Bahkan di perkirakan ilmu ini telah dikenal sejak awal manusia diciptakan di dunia, mungkin karena pijat berhubungan sangat erat dengan kehamilan dan proses kelahiran manusia (Roesli, 2001). Pemijatan adalah teknik relaksasi yang lembut dan jarang menyebabkan efek samping ( Trans, 2001, dalam Hizkia, 2007).

\section{DAFTAR PUSTAKA}

Alimul, Aziz. 2007. Metode Penelitian Kebidanan \& Tehnik Analisis Data. Jakarta : Salemba Medika.

Budiarto, Eko. 2007. Biostatistik Untuk Kedokteran dan Kesehatan Masyarakat. EGC : Bandung

Depkes RL. 2010. Pedoman operasional penanggulangan anemia gizi di Indonesia Jakarta : Dirjen Binkesmas

Gichara, J. 2006. Manfaat Pijat Bayi pasca melahirkan . Jakarta: Papas Sinar Sinanti 
Notoatmodjo S. 2007. Promosi Kesehatan dan Ilmu Perilaku. Jakarta : PT. Rineka Cipta.

Notoatmojo, S. (2010). Metodologi Penelitian Kesehatan Cetakan ke-3. Jakarta: PT. Rineke Cipta

Nursalam, (2007), Konsep dan penerapan metodologi penelitian ilmu keperawanan. Jakarta : Salemba Medika.

Nursalam. 2008. Konsep dan Penerapan Metodologi Penelitian Ilmu Keperawatan. Surabaya : Salemba Medika

Nursalam. 2011. Konsep dan Penerapan Metodologi Penelitian Ilmu Keperawatan, Edisi II. Salemba Medika. Jakarta

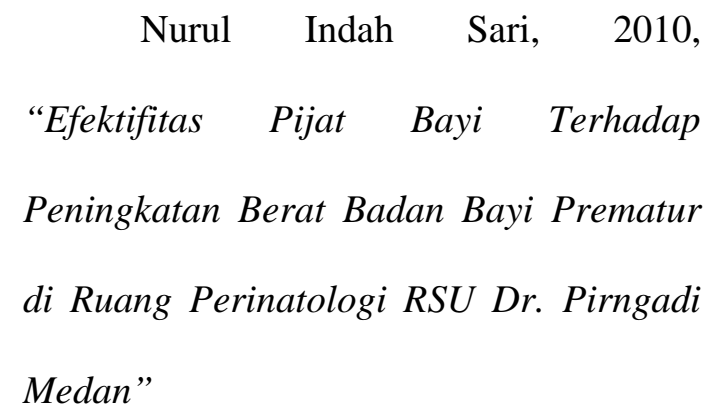

Nurul Indah Sari, 2010, lembut untuk mempertahankan kesehatan dan ketenangan bayi usia 3bulan ke atas. Banyu Media. Yogyakarta. 